\title{
A Marine-Biology-Centric Definition of Ocean Connectivity and the Law of the Sea
}

\author{
Elise Johansen, * Irene V. Dahl, Alexander Lott, \\ Philipp Peter Nickels and Ingrid Solstad Andreassen \\ UiT The Arctic University of Norway
}

\begin{abstract}
The inter-connectedness of marine ecosystems has been repeatedly acknowledged in the relevant literature as well as in policy briefs. Against this backdrop, this article aims at further reflecting on the question of to what extent the law of the sea takes account of or disregards ocean connectivity. In order to address this question, this article starts by providing a brief overview of the notion of ocean connectivity from a marine science perspective, before taking a closer look at the extent to which the law of the sea incorporates the scientific imperative of ocean connectivity in the context of four examples: (i) straits, (ii) climate change and ocean acidification, (iii) salmon and (iv) the ecosystem approach to fisheries. Tying the findings of the different examples together, this study concludes by stressing the need of accommodating ocean connectivity not only in the interpretation and implementation of the existing law (of the sea) but also in its further development.
\end{abstract}

Keywords: ocean, connectivity, ecosystem approach, climate change, ocean acidification, straits, fisheries, salmon, LOSC, land-sea interface

Responsible Editor: Margherita Paola Poto, UiT The Arctic University of Norway

Received: June 2021; Accepted: August 2021; Published: November 2021

The paramount importance of acknowledging ocean connectivity, which can as a first approximation be understood as "describing the interlinked nature of the ocean", ${ }^{1}$ has been repeatedly acknowledged in the relevant literature ${ }^{2}$ as well as in policy briefs. ${ }^{3}$ Against this backdrop, this article aims at further reflecting on the question of to what extent the law of the sea takes account of or disregards ocean

\footnotetext{
^Correspondence to: Elise Johansen, e-mail: elise.johansen@uit.no

(C) 2021 Elise Johansen, Irene V. Dahl, Alexander Lott, Philipp Peter Nickels and Ingrid Solstad Andreassen. This is an Open Access article distributed under the terms of the Creative Commons CC-BY 4.0 License. eISSN 2387-4562. https:// arcticreview.no.

Citation: Elise fohansen, Irene V. Dahl, Alexander Lott, Philipp Peter Nickels and Ingrid Solstad Andreassen. "A Marine-BiologyCentric Definition of Ocean Connectivity and the Law of the Sea" Arctic Review on Law and Politics, Vol. 12, 2021, pp. 190-206. http://dx.doi.org/10.23865/arctic.v12.3292
} 
connectivity. In order to address this question, the article starts by providing a brief overview of the notion of ocean connectivity from a marine science perspective (section 1), before taking a closer look at the extent to which the law of the sea incorporates the scientific imperative of ocean connectivity in the context of four examples: (i) straits, (ii) climate change and ocean acidification, (iii) salmon and (iv) the ecosystem approach to fisheries in areas beyond national jurisdiction (section 2). Tying the findings of the different examples together, the third and final section concludes by stressing the need to accommodate ocean connectivity not only in the interpretation and implementation of the existing law (of the sea), but also in its further development.

\section{Model's characteristics}

As rightly stressed by a recent UNEP report on ocean connectivity, "[i]n the marine realm, movement between ecosystems is largely unobstructed by obvious physical boundaries", and as a consequence, "all parts of the global ocean are interconnected". ${ }^{4}$ Building on this realization, the following provides a brief overview of how the notion of ocean connectivity can be understood from a (marine) science perspective by distinguishing between (i) active and passive connectivity, (ii) vertical and horizontal dimensions of connectivity and (iii) three types of migratory connectivity. This will lay the groundwork for section 2, which asks to which degree the law of the sea takes into account ocean connectivity understood in (marine) science terms, as opposed to different understandings of connectivity, which are the focus of articles 2 and 3 of this special issue.

\subsection{Active and passive connectivity}

To better understand the notion of ocean connectivity, a distinction can be made between passive and active connectivity. Passive connectivity describes the phenomenon of the "transportation of material such as nutrients, small marine organisms and other marine organisms by ocean currents and processes such as sinking and upwelling". ${ }^{5}$ Passive connectivity is also known as oceanographic connectivity, ${ }^{6}$ deriving from oceanography, which is the study of physical and biological aspects of the ocean. ${ }^{7}$ Active connectivity, on the other hand, refers to the phenomenon of the migration of marine species and marine organisms, and more specifically to "the movement of marine animals across the ocean and up and down through the water column". 8

By marking the limit of one ocean and the beginning of another, straits play a key role in understanding how AC and PC work, and how they can be enabled or restricted. Straits also connect roughly a third of 66 internationally recognized large marine ecosystems $s^{9}$ (hereafter LMEs) with one another. For example, in Europe alone, five straits connect eight LMEs, as shown in the table below. 
Table 1. Straits as connectors of different levels of marine ecosystems ${ }^{10}$

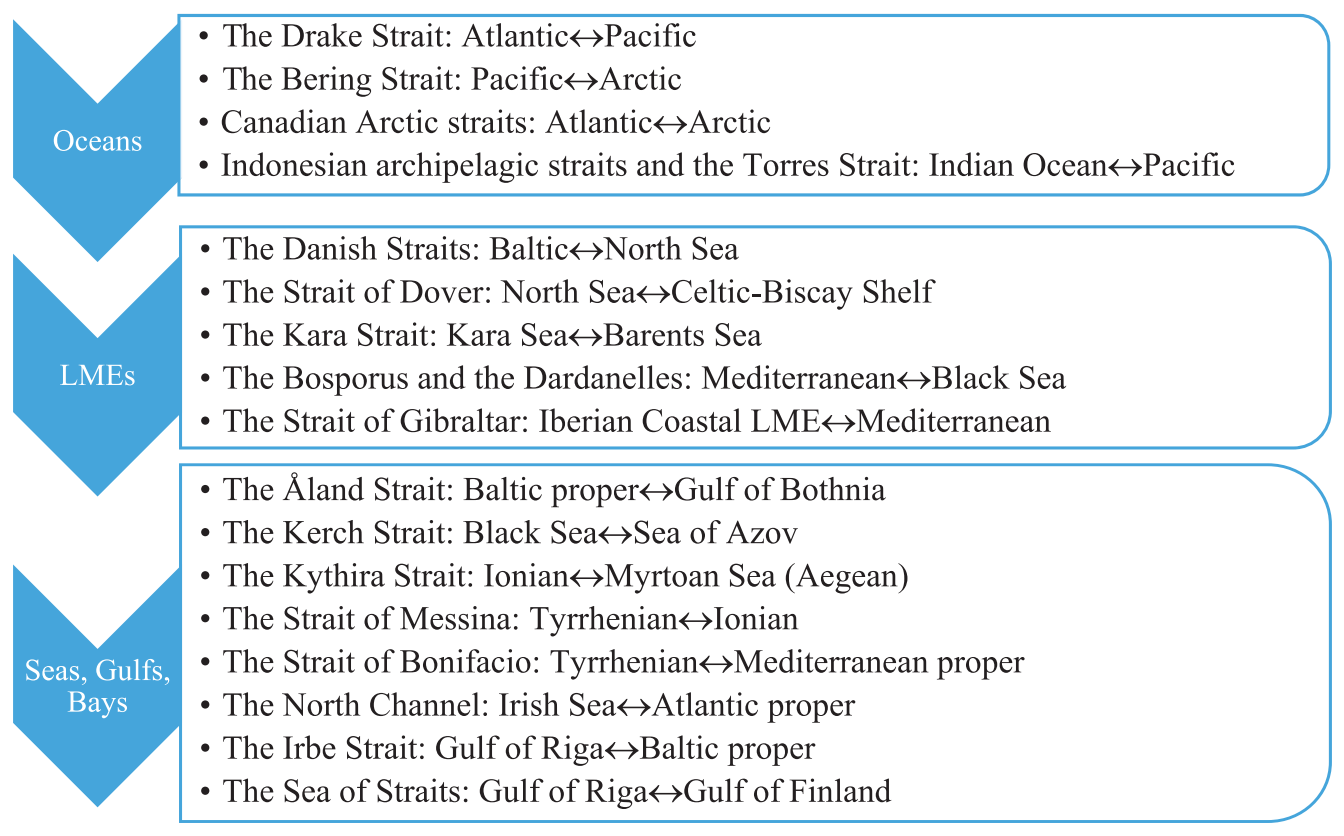

Straits are particularly important for LMEs that comprise semi-enclosed seas (Article 122 of the UN Convention on the Law of the Sea, hereinafter LOSC), ${ }^{11}$ e.g. the Baltic Sea, the Mediterranean, and the Black Sea. For these semi-enclosed LMEs, straits are the primary lifeline to the world's oceans. For example, the water changes in the Baltic Sea approximately every 30 years via the inflow of freshwater that carries along nutrients and other organisms through the Danish straits. ${ }^{12}$ In the Mediterranean, the so-called complete thermohaline circulation takes about 100 years, whereas in the Black Sea this period lasts approximately 2500 years. Within the LMEs, straits also connect smaller ecosystems of seas, gulfs, and bays with one another. Straits of the northern Baltic Sea - the Åland Strait, the Viro Strait, the Irbe Strait, and the Sea of Straits - connect the Gulf of Bothnia, the Gulf of Finland, and the Gulf of Riga with the Baltic Sea proper. The characteristics of such smaller ecosystems may significantly differ from their respective broader LME. For example, in contrast to the other parts of the Baltic Sea, the complete thermohaline circulation in the Gulf of Bothnia takes only about 4 years due to the great influx of freshwater from rivers. Low salinity levels also lead to increased ice cover, which is an important habitat factor for some of the species that commute between the various gulfs of the northern Baltic Sea, e.g. seals. Reportedly, seals also use straits as foraging sites. For example, grey seals swim daily over 60 nautical miles (nm) from their haul-out on Allirahu islets deep in the northern Gulf of Riga to visit the fish-rich shoals of the Irbe Strait. ${ }^{13}$ Straits serve as important channels that allow organisms 
to freely change their habitats and exchange individuals between sub-populations. This is necessary for the proper functioning of marine ecosystems.

\subsection{The vertical and horizontal dimensions of connectivity}

A second distinction can be made between a vertical and horizontal dimension of ocean connectivity. ${ }^{14}$ The backdrop for this distinction is that oceans lack for the most part "obvious physical boundaries" between oceanic ecosystems, except in some instances where the gateways to the neighbouring oceanic ecosystems are relatively narrow. ${ }^{15}$ This general lack of physical boundaries between ocean ecosystems allows for "horizontal and vertical movements" between not only the open ocean and coastal waters, but also the deep sea. ${ }^{16}$ These movements between ecosystems are central for "maintaining healthy and productive ecosystems" ${ }^{17}$ A point that will be discussed in section 2 is to which extent the law of the sea with its zonal approach to jurisdiction pays sufficient attention to vertical and horizontal movements across jurisdictional boundaries.

In addition, an understanding of ocean connectivity must go further than acknowledging vertical and horizontal movements in the ocean. The reason for this is that connectivity extends beyond the ocean in light of interlinkages between ocean and atmosphere, ocean and land, and ocean and rivers. For instance, it has been pointed out that " $[\mathrm{t}] \mathrm{he}$ land and sea are inherently connected via multiple, complex, social-ecological interactions". ${ }^{18}$ And indeed, climate change as well as the related problem of ocean acidification, which can be defined as the "reduction in the $\mathrm{pH}$ of the ocean, accompanied by other chemical changes, [...] caused primarily by uptake of carbon dioxide $\left(\mathrm{CO}_{2}\right)$ from the atmosphere", ${ }^{19}$ are two examples in point.

The ocean and atmosphere work together to move heat and freshwater across the globe. Wind-driven and ocean-current circulations move warm water toward the poles and colder water toward the equator. The ocean can store a higher volume of heat compared to the Earth's land surfaces. Most of the thermal energy at the Earth's surface is stored in the ocean. Thus, the absorption and movement of energy on the Earth is related to the ocean-atmosphere system. Understanding ocean-atmosphere coupling is hence critical for predicting changes in global temperature patterns and the different properties of climate variability that accompany global warming. ${ }^{20}$

The ocean has very likely absorbed "between $20-30 \%$ [...] of total anthropogenic $\mathrm{CO}_{2}$ emissions since the $1980 \mathrm{~s}$, ${ }^{21}$ further illustrating the crucial role the ocean plays in the world's climate system, but which has also led to ocean acidification. Even though $\mathrm{CO}_{2}$ emissions from the shipping and the aviation sectors further contribute to ocean acidification, the lion's share of $\mathrm{CO}_{2}$ emissions, which lead to climate change and ocean acidification, originates from land-based sources in the form of atmospheric pollution. At the regional level, ocean acidification can also be caused by land-based pollution, such as agricultural runoffs. ${ }^{22}$ It follows that mitigating 


\section{Elise fohansen et al.}

ocean acidification and climate change more generally is a pressing "cross-system" challenge of the land-sea interface, ${ }^{23}$ and the two examples further illustrate the importance of acknowledging connectivity beyond the ocean itself.

Another example of connectivity across the land-sea interface is the connectivity between rivers and the ocean in the context of migratory fish stock. From a regulatory perspective, rivers are mostly treated as part of a state's land territory, while oceans are subject to the law of the sea regime. This creates a contextual starting point for regulatory approaches that leaves out the clear interlinkages that remain between the ocean and rivers. The actual movement of the Atlantic salmon is one example. The Atlantic salmon travels thousands of miles to the North Atlantic feeding grounds (arrows), usually near western Greenland. They remain there for one to three years before returning to their home river to reproduce. ${ }^{24}$ Thus, they occur both within the maritime zones of several states and rivers in the Atlantic Ocean region.

\subsection{Three types of migratory connectivity}

A third, and for our purposes final, distinction can be made between three types of migratory connectivity based on Dunn et al., ${ }^{25}$ who build on the biological definition provided by Webster et al. in 2002. ${ }^{26}$ The first type is migratory connectivity, stricto sensu, which identifies seasonal movements of individual fish between breeding and post-breeding, foraging sites.

The second type is landscape (and reasonably seascape) connectivity, which identifies the regional movements of individuals among habitat patches. The third type is the so-called natal dispersal, which identifies the spread of individuals from birth sites to breeding sites. More accurately, to remain faithful to Webster et al.'s text, ${ }^{27}$ migratory connectivity differs from landscape connectivity on both a spatial scale (involving much larger distances than the landscape), and on a temporal scale, being cross-seasonal, while landscape connectivity involves movements of individuals within a season. The natal dispersal, according to Webster et al., is a concept used in fisheries literature, where it often refers to natal dispersal from one population to another. ${ }^{28}$ Natal dispersal seems to be the result of two grounds of migratory movements, involving the movement of newborns to wintering grounds and then back to a summer population for first breeding.

The biological assumption presented by Webster et al. and Dunn et al. indicates that multiple migratory marine species exhibit at least one of three forms of connectivity, highlighting the importance of this concept for regulatory purposes. A global snapshot of fishery production reached a record of 96.4 million tons in $2018 .{ }^{29} \mathrm{At}$ the same time, an examination of the various stocks worldwide showed that 34.2 percent of fishery resources are exploited at biologically unsustainable levels. ${ }^{30}$ The 'ecosystem approach to fisheries' has become a benchmark for sustainable fisheries management, and can be defined as 


\section{A Marine-Biology-Centric Definition of Ocean Connectivity and the Law of the Sea}

an extension of conventional fisheries management recognizing more explicitly the interdependence between human well-being and ecosystem health, and the need to maintain ecosystems productivity for present and future generations, e.g. conserving critical habitats, reducing pollution and degradation, minimizing waste, and protecting endangered species. ${ }^{31}$

The ecosystem approach to fisheries thus, at least in theory, embraces the core elements of migratory connectivity by focusing on the interlinkage between marine species, the ecosystems that sustain them, their habitats, and breeding sites. The approach further comprises a framework of management objectives and conceptual goals, which inform governance and area-based management.

\section{How the law (of the sea) and governance take into account or disregard ocean connectivity}

Based on the different understandings of connectivity from a (marine) science perspective, the following reflects on the extent to which the law of the sea takes account of connectivity in the context of the four examples mentioned above. Before turning to the first example of straits, it needs to be acknowledged that scholars have already reflected on the role that ocean connectivity plays in the law of the sea, which provides the basis for our discussion. For instance, Harden-Davies et al. have already pointed to examples where ocean connectivity is, to some degree, recognized by the law of the sea. ${ }^{32}$ One such example is that the LOSC recognizes in its Preamble, "that the problems of ocean space are closely interrelated and need to be considered as a whole". ${ }^{33}$ This recognition notwithstanding, it has already been repeatedly stressed in the literature that the zonal approach of the LOSC to maritime jurisdiction, ${ }^{34}$ together with the fragmented nature of different sectors/issues of international law, is not based on ecological considerations, such as ocean connectivity. ${ }^{35}$ Yet, the UN Fish Stock Agreement (hereinafter 1995 UNFSA), ${ }^{36}$ which was adopted as an implementation agreement under the LOSC, responded to the lack of any explicit recognition of the ecosystem approach in the LOSC and has been mentioned as another example of where the law of the sea recognizes ocean connectivity. ${ }^{37} \mathrm{~A}$ final example for present purposes is the Convention on Biological Diversity (CBD), ${ }^{38}$ which adopted an ecosystem approach. ${ }^{39}$ Following these general remarks, which provide a mixed picture of the degree to which the law (of the sea) takes into account connectivity, it is now time to turn to the four concrete examples, starting with straits.

The legal regime of straits is anthropocentric in nature and focuses on societal connectivity (navigation, bridges, tunnels, pipelines, cables) with an emphasis on safeguarding the passage rights of ships and aircraft in chokepoints of international navigation. The regulation of straits has mainly been driven by economic and military considerations due to the strategic importance of straits for the world economy and security. The significance of straits as connectors of ecosystems and habitats has 


\section{Elise Fohansen et al.}

not received equal recognition, leading some authors to conclude that environmental problems are neglected in Part III of the LOSC. ${ }^{40}$ Nonetheless, the LOSC can be subjected to an evolutionary interpretation to ensure that the marine-biological perspective is encompassed in the way straits are viewed and regulated today.

In this context, risks to straits as connectors of ecosystems and habitats can be mitigated by, inter alia, the application of the ecosystem-based approach to maritime spatial planning ${ }^{41}$ the use of environmental impact assessments in industrial development processes, and the designation of marine protected areas as well as particularly sensitive sea areas (PSSA) in straits and regions in close proximity. States are allowed to adopt laws on the prevention, reduction, and control of vessel-source pollution in a strait (see Article 42(1) of the LOSC), violations of which can be sanctioned with due enforcement measures (Article 233 of the LOSC). To preserve the marine environment in straits with heavy traffic, strait states should strive to establish a proper traffic separation scheme, mandatory ship reporting system, or compulsory pilotage. ${ }^{42}$ Implementing the above-listed measures by strait states should be encouraged to ensure that industrial navigation and human activity through straits will not result in the obstructed movement of marine organisms between ecosystems.

The land-sea and atmosphere-ocean interfaces present another example where the degree to which the law of the sea takes account of connectivity is questionable. Despite the critical role that oceans play in climate regulation, international climate law and the law of the sea have developed as two different, largely separate, legal regimes. This is perhaps one of the greatest challenges when it comes to how the law of the sea considers ocean connectivity with regard to climate change - the lack of regime interaction..$^{43}$ The lack of regime interaction presents a twofold dilemma; on the one hand, the LOSC is intended to cover all matters related to the oceans, without expressly referring to climate change; on the other hand, the UN Climate Change Regime is meant to cover matters related to climate change, which is highly terrestrial and atmospheric in scope, and with very limited application to the oceans. However, the physical relationship between the oceans and climate is indisputable. While the risks and consequences of climate change regarding the oceans continue to grow, it remains unclear whether the existing international legal framework is capable of properly dealing with these threats.

Even though the LOSC does not mention the ecosystem approach and ocean connectivity per se, there are Articles in the LOSC Part XII (e.g. Articles 192, 207, 212,213 , and 222) that demonstrate an understanding of the need to take a holistic approach to manage pollution, including climate change. The LOSC considers (ocean) connectivity within the limited context of land-based sources of atmospheric and land-based pollution. This can be illustrated by the example of ocean acidification. ${ }^{44}$ The LOSC applies to land-based pollution and atmospheric pollution, including ocean acidification, even though these sources of pollution originate from state territories ${ }^{45}$ This follows from Articles 207 and 212 of the LOSC, which address - albeit in vague terms - land-based and atmospheric pollution. ${ }^{46}$ However, 
as stressed by Scott, "Articles 207 and 212 [...] neither establish global standards nor require states to comply with any such standards adopted" ${ }^{47}$ This absence of any concrete standards means that the substantive role of the LOSC in terms of mitigating ocean acidification is to some degree a "matter of interpretation" ${ }^{48}$ While some scholars have argued that the LOSC merely obliges its state parties to implement the UN Climate Change Regime, but does not impose stringent obligations, ${ }^{49}$ others suggest that the LOSC, in fact, stipulates a due diligence obligation to take measures against ocean acidification, which is not met by simply complying with the obligations of the UN Climate Change Regime..$^{50}$ It follows for present purposes that the extent to which the law of the sea considers connectivity between the land and sea in the context of ocean acidification is similarly subject to interpretation. That said, it is noteworthy that the LOSC and more broadly the law of the sea are not the only relevant sources for ocean acidification. Instead, ocean acidification "cuts across and falls between international regimes with mandates to protect the atmosphere, the ocean and biodiversity" ${ }^{51}$ Besides the LOSC, the United Nations Framework Convention on Climate Change (UNFCCC), ${ }^{52}$ the Kyoto Protocol, ${ }^{53}$ and the Paris Agreement ${ }^{54}$ as well as the CBD are all relevant for the regulation of ocean acidification. ${ }^{55}$ Furthermore, Goal 14 of the Sustainable Development Goals $(\mathrm{SDGs})^{56}$ can be seen as an example of a non-binding instrument addressing ocean acidification. ${ }^{57}$ Against this backdrop, Scott suggests conceptualizing the current regulatory setting for ocean acidification as a 'regime complex', ${ }^{58}$ a concept originally introduced by Raustiala and Victor. ${ }^{59}$ Defined as "an array of partially overlapping and non-hierarchical institutions governing a particular issue area", ${ }^{60}$ a regime complex consists of different "elementary regimes", which are relevant to a particular issue-area; however they are "created and maintained in distinct fora with the participation of different sets of actors" ${ }^{61}$ Here, Scott further observes a key challenge in generating "meaningful linkages and connections" between the different relevant regimes of ocean acidification. ${ }^{62}$

Turning back to the question of connectivity in the context of ocean acidification and climate change, the following points can be concluded. First, because different regimes or areas of international law are relevant for mitigating ocean acidification and climate change, it follows that the question of the extent to which international law takes account of connectivity across the land-sea and ocean-atmosphere interface in this regard is not limited to investigating the law of the sea, but also includes, for instance, an investigation of the UN Climate Change Regime. Second, in the context of mitigating climate change and the related problem of ocean acidification caused by atmospheric pollution from land-based sources and land-based pollution, it appears that connectivity across the land-sea and atmosphere-ocean interface is not strongly emphasized in the regulatory approach of the law of the sea and there is also a low degree of legal interplay between the law of the sea regime and the UN Climate Change Regime in this regard. Nonetheless, the LOSC contains provisions that deal with pollution stemming from the atmosphere and from land-based pollution, which 


\section{Elise Fohansen et al.}

means that the degree to which the law of the sea considers connectivity across the atmosphere-ocean and land-sea interface is arguably a matter of interpretation.

A second example of the land-sea interface that raises questions about the extent to which connectivity is sufficiently considered by the law of the sea is the example of anadromous fish stock. In the LOSC there is a lack of systematization of landand-sea interactions, and this loophole affects the adoption and implementation of integrated management approaches to sea, coastal, and inland activities, and all interactions between them. Such a shortcoming can be found in the regulation of Atlantic salmon and other ecosystem approaches to fisheries. The Atlantic salmon is an anadromous species, hatching in streams and rivers but moving out to sea as it grows. Article 66 of the LOSC offers a limited definition of the state of origin's obligation in relation to the anadromous stock. This provision recognizes that the state of origin has a primary interest in, and responsibility for, such stocks. Further, the state of origin is obliged to ensure the conservation of these stocks through "the establishment of appropriate regulatory measures for fishing in all waters landward of the outer limits of its exclusive economic zone". This duty applies to the exclusive economic zone (EEZ) and the territorial sea of the coastal states. However, when it comes to a holistic approach regarding salmon management in ocean and freshwater, the question is whether the obligation to establish conservation measures extends to rivers, as the wording "waters" does not cover rivers. It is doubtful whether Article 66 of the LOSC applies to freshwater, which translates into a lack of integrated conservation measures. However, an obligation to apply a holistic/ecosystem-based principle to salmon management may derive from the CBD. The preamble of the CBD states that, "the fundamental requirement for the conservation of biological diversity is the in-situ conservation of ecosystems and natural habitats and the maintenance and recovery of viable populations of species in their natural surroundings". Further, according to Article $8(\mathrm{~d})$ of the CBD, the parties shall " $[\mathrm{p}]$ romote the protection of ecosystems, natural habitats, and the maintenance of viable populations of species in natural surroundings". The CBD defines the ecosystem approach as a strategy for the integrated management of land, water, and living resources that promotes conservation and sustainable use in an equitable way. ${ }^{63}$ Thus, an international law obligation exists that encourages an ecosystem approach to the management of biological resources, such as, anadromous fish stocks.

In literature-based definitions of the 'ecosystem approach to fisheries' it is often stressed that, the ecosystem approach to fisheries embraces the core elements of migratory connectivity by focusing on the interlinkage between marine species, the ecosystems that sustain them, their habitats and breeding sites. Because of their migratory nature, this is also relevant to the Atlantic salmon. While the provisions of the CBD show an opening towards an integrated approach to fisheries (at least in relation to the Atlantic salmon), the complexity and fragmentation of the legal provisions applicable to ocean connectivity demand consideration towards the development of an integrated and systematic approach to ocean activities. 
The lack of explicit referencing to the term 'ecosystem approach' in the LOSC has created some impediments for conventional fisheries on the high seas. ${ }^{64}$ Nevertheless, the law of the sea regime has established a "vehicle" for the operationalization of the 'ecosystem approach to fisheries' in areas beyond national jurisdiction by the adoption of the 1995 UNFSA. The 1995 UNFSA calls for transnational cooperation through Regional Fisheries Management Organizations (RFMOs) and requires state parties to protect biodiversity in the marine environment and adopt measures to protect species belonging to the same ecosystems. ${ }^{65}$ The 1995 UNFSA is thus one example where the law of the sea has been developed in such a way as to explicitly take account of biological connectivity through long-term conservation and sustainable use of the relevant species. Nevertheless, challenges remain with regard to implementation and operationalization of the approach despite formal acknowledgement by its inclusion in the 1995 UNFSA.

The ecological principles listed in Article 5 of the 1995 UNFSA are binding upon the state parties ${ }^{66}$ However, states have discretion and freedoms when it comes to the actual implementation of these obligations ${ }^{67}$ The measures to fulfil the obligation to implement an ecosystem approach to fisheries are vague, and it is difficult to monitor, survey and enforce that flag states operating on the high seas are fulfilling their duties under the Agreement. It thus seems unclear whether the 1995 UNFSA does justice to the marine ecosystems it purports to conserve through the ecosystem considerations incorporated in the instrument.

Nevertheless, the Food and Agriculture Organization of the United Nations (FAO), a specialized agency of the United Nations, can be considered a pioneer in making the 'ecosystem approach to fisheries' functional by the adoption of the integrated framework for fisheries in the $1995 \mathrm{FAO}$ Code of Conduct. ${ }^{68}$ The instrument functions as a reference framework for sustainable fisheries, addressing all of the ecosystem considerations, principles and conceptual goals necessary for applying an 'ecosystem approach to fisheries' ${ }^{69}$ In the aftermath of its adoption, the FAO has developed several technical guidelines, monitoring systems and forums to operationalize the approach. Through the identification of scientific and legal tools and management measures, the requirements necessary for applying the approach have, to a large extent, been crystallized. ${ }^{70}$

Despite the identification of these scientific and legal requirements, and even though there exist numerous different RFMOs, it seems that targeted fish stock keep declining, with a serious impact on high seas ecosystems. Overfishing and ecological extinction have led to the collapse of marine ecosystems, "raising the possibility that many more marine ecosystems may be vulnerable to collapse in the near future" ${ }^{71}$ At present, it is evident that one of the threats to marine ecosystems in areas beyond national jurisdiction is the lack of operationalization of the ecosystem approach to fisheries.

RFMOs have the competence to establish legally binding conservation and management measures for their contracting parties and cooperating non-parties in areas 


\section{Elise fohansen et al.}

beyond national jurisdiction. ${ }^{72}$ It is thus clear that these organizations should intensify actions to maintain the biological connectivity taking place in these areas, by incorporating the various tools and management measures identified by the FAO, in order to actually implement and operationalize the ecosystem approach to fisheries in line with the framework set forth by the adoption of the 1995 Code of Conduct and the 1995 UNFSA.

A concrete example of gaps between the legal and policy framework on the one hand, and the practice by some of the RFMOs on the other, is illustrated by the operationalization of the conceptual goal of prevention of abandoned, lost and discarded fishing gear. ${ }^{73}$ In Article 7.6.9 of the Code of Conduct, it is expressly stated that "states should take appropriate measures to minimize catch by lost and abandoned gear". Article 7.2.2 emphasizes that such catch should be minimized to the extent practicable, and that the "development and use of selective, environmentally safe and cost-effective fishing gear and techniques" should be promoted. Further, in the 1995 UNFSA, it explicitly states that high seas fishing nations shall minimize "catch by lost or abandoned gear". ${ }^{74}$

It is thus evident that the legal and policy framework that currently addresses the serious problems of catch by such gear leave state parties with an obligation to combat such 'fishing'. Concrete management measures dealing with the prevention of catch by lost or abandoned gear include the enforcement of a prohibition on gear dumping at sea, establishment of gear disposal systems in landing places and procedures to systematically recuperate lost gear. ${ }^{75}$ Nevertheless, several case-studies reveal that many RFMOs have not adopted the necessary measures to control the prevention of catch by abandoned, lost or discarded fishing gear. ${ }^{76}$ The RFMOs that currently lack binding measures to control catch by such gear should thus strive to fill the gap between legal and policy obligations, and the practices of these organizations, in order to give effect to the instruments that will do justice to the ecosystems they purport to conserve in the future.

\section{Acknowledging ocean connectivity}

Building on the existing literature, which has already highlighted the paramount importance of acknowledging ocean connectivity as well as connectivity across the atmosphere-ocean and land-sea interfaces, this article has highlighted different understandings of connectivity. In light of what one might refer to as the scientific imperative of accommodating considerations of (ocean) connectivity in the international legal framework for the ocean as well as for interlinkages between the ocean, atmosphere and land, this article zoomed in on four examples to explore whether the existing law (of the sea) takes account of the question of connectivity.

The different examples in the preceding section demonstrate that the answer to this question is not simply yes or no, but rather a nuanced one. As discussed in the preceding section, the law of the sea faces some inherit and rather obvious 
constraints when it comes to questions of (ocean) connectivity. One prime example is its zonal and sectoral approach, which at first glance appears squarely at odds with the notion of connectivity. The example of the ecosystem approach to fisheries is, however, a clear example of how the development of the law of the sea has taken into account considerations of connectivity by virtue of recognizing the ecosystem approach to fisheries not only prominently in the 1995 UNFSA, but also in various RFMO/As. However, even where the law formally recognizes connectivity, challenges remain. For instance, implementing the ecosystem approach to fisheries has proven to be a difficult task due to many and varying factors such as lack of scientific knowledge, and lack of political will to prioritize, adopt and enforce necessary measures. ${ }^{77}$ Another example is the case of Atlantic salmon, regulated in a fragmented manner (LOSC, CBD) and only belatedly framed within an integrated system approach (CBD).

In addition to examples where the law of the sea explicitly recognizes ocean connectivity, this article has shown that the degree to which the law of the sea considers ocean connectivity depends on the subject matter in question and is, in some cases, a matter of interpretation. A clear example of the latter point is the example of climate change and the related problem of ocean acidification. This, of course, comes with its own challenges, since a more explicit recognition of connectivity could prevent interpretative difficulties when determining the substantive standard of what is required by states to mitigate climate change and ocean acidification under the law of the sea. Another point to remember is that any discussion of the extent to which the law of the sea considers connectivity across the land-sea and atmosphere-ocean interface takes place against the backdrop of the different focus of the law of the sea and the UN Climate Change Regime. While the former is, as mentioned above, primarily concerned with the world's oceans, the latter has a terrestrial and atmospheric focus. This is evident from the fact that the UN Climate Change Regime formulates a temperature goal of 1.5 degrees for the atmosphere, while it notably lacks both temperature and $\mathrm{pH}$ level goals for the ocean. ${ }^{78}$ While this definitively constitutes a problem, it is noteworthy that this discrepancy in focus between the law of the sea and the UN Climate Change Regime can, to some extent, be bridged when implementing the respective obligations of the law of the sea and the climate change regime. For instance, it has been observed that the nationally determined contributions under the Paris Agreement submitted by its state parties increasingly take ocean aspects into account. ${ }^{79}$

The importance of interpreting as well as implementing the existing law of the sea in a way that takes account of considerations of connectivity can further be illustrated in the context of the regulation of salmon. Here, a systematic interpretation of different norms opens the door to the discourse that includes salmon-related activities within an integrated framework. The second example is the case of straits. In the discussion above, it was demonstrated how interpretations of the LOSC's provisions can be extended to include considerations of ocean connectivity. If one looks 


\section{Elise fohansen et al.}

at ocean connectivity from a marine-biology-centric approach, the classification of straits can expand beyond mere navigational purposes. A strait can be evaluated and regarded as a critical contributor to the connectivity of ocean ecosystems, LMEs, and smaller ecosystems of seas, gulfs, and bays. The marine environment of straits is under pressure from human industrial activities. The coastal areas of straits tend to be the location of major human settlements, which leads to increased levels of pollution, particularly from land-based sources. An extensive interpretation of the provisions on straits that looks at the marine-biology-centric connectivity can help mitigate the risks posed by such environmental threats.

To conclude, the systemic challenges ocean ecosystems are facing require the international legal framework to acknowledge and accommodate the scientific imperative of ocean connectivity. For the LOSC to be able to live up to its reputation of being a dynamic and modern instrument, it is absolutely necessary to demonstrate its ability to accommodate considerations of ocean connectivity in its interpretation. Here, an integrated approach to marine biology and ocean governance is needed to direct an extensive interpretation of the law of the sea, one that ascribes the same value to societal considerations as to ecological ones, and that seeks to integrate and balance the protection of the two within the ecosystem..$^{80}$ In addition to interpretation, accommodating considerations of ocean connectivity is further crucial when implementing and enforcing the existing law of the sea, as well as in its future development. While beyond the scope of this article, the ongoing international negotiations aimed at developing a legally binding instrument on the conservation and sustainable use of biodiversity in areas beyond national jurisdiction provide a crucial opportunity for the latter. ${ }^{81}$

\section{NOTES}

1. UNEP, "Connectivity: A Critical Biodiversity Consideration in Global Ocean Sustainability," https://www.unep-wcmc.org/system/comfy/cms/files/files/000/001/498/original/3207_ Technical_Brief_Edited_Web.pdf (accessed 31 May 2021), 1.

2. See, e.g., Harriet Harden-Davies et al., "Rights of Nature: Perspectives for Global Ocean Stewardship," Marine Policy 122 (2020): 4.

3. See, e.g., UNEP, "Connectivity: A Critical Biodiversity Consideration in Global Ocean Sustainability,".

4. Ibid., 2 .

5. Ibid., 3. See also, Ernesto Villarino et al., "Large-scale Ocean Connectivity and Planktonic Body Size," Nature Communication 142 (2018): 1-13.

6. Manuel Hidalgo et al., "Advancing the Link between Ocean Connectivity, Ecological Function and Management Challenges," ICES fournal of Marine Science 74 (2017): 1702.

7. For an updated review of active and passive connectivity, see Elina A. Virtanen, Atte Moilanen and Markku Viitasalo, "Marine Connectivity in Spatial Conservation Planning: Analogues from the Terrestrial Realm," Landscape Ecology 35 (2020): 1021-1034.

8. UNEP, "Connectivity: A Critical Biodiversity Consideration in Global Ocean Sustainability," 3; Bethan C. O’Leary and Callum M. Roberts, "Ecological Connectivity across 


\section{A Marine-Biology-Centric Definition of Ocean Connectivity and the Law of the Sea}

Ocean Depths: Implications for Protected Area Design," Global Ecology and Conservation 15 (2018): 1-10.

9. See, e.g., IUCN et al., "Large Marine Ecosystems of the World and Linked Watersheds," Scale 1:31,700,000, https://celebrating200years.noaa.gov/breakthroughs/ecosystems/lme_ map.jpg (accessed 31 May 2021).

10. Map created by Alexander Lott.

11. United Nations Convention on the Law of the Sea (adopted 10 December 1982, entered into force 16 November 1994) 1833 UNTS 3.

12. HELCOM, "State of the Baltic Sea - Holistic Assessment," http://stateofthebalticsea.helcom.fi/in-brief/our-baltic-sea/ (accessed 31 May 2021).

13. Mart Jüssi, "Uusmadala, Kuradimuna madala ja Tallinna madala piirkonna mereala inventeerimine: eksperthinnang uuritava ala olulisuse kohta mereimetajatele," (2013) https:// issuu.com/elfond/docs/mereimetajad_tln_madalad_aruanne (accessed 31 May 2021), 4.

14. UNEP, "Connectivity: A Critical Biodiversity Consideration in Global Ocean Sustainability," 1 .

15. See supra Table 1.

16. UNEP, "Connectivity: A Critical Biodiversity Consideration in Global Ocean Sustainability," 1 .

17. Ibid.

18. Jeremy Pittman and Derek Armitage, "Governance across the Land-Sea Interface: A Systematic Review," Environmental Science and Policy 64 (2016): 9 with further references.

19. IPCC, "The Ocean and Cryosphere in a Changing Climate, A Special Report of the Intergovernmental Panel on Climate Change," (2019) https:/www.ipcc.ch/site/assets/uploads/ sites/3/2019/12/SROCC_FullReport_FINAL.pdf (accessed 31 May 2021), 693.

20. Vidas et al., "Climate Change and the Anthropocene - Implications for the Development of the Law of the Sea," in The Law of the Sea and Climate Change, Solutions and Constraints, eds. Elise Johansen, Signe V. Busch and Ingvild U. Jakobsen (Cambridge: Cambridge University Press, 2020) Ch. 2.

21. IPCC, "The Ocean and Cryosphere in a Changing Climate, A Special Report of the Intergovernmental Panel on Climate Change," 9.

22. Karen N. Scott, "Ocean Acidification: A Due Diligence Obligation under the LOSC," The International fournal of Marine and Coastal Law 35 (2020): 406.

23. Pittman and Armitage, "Governance across the Land-Sea Interface: A Systematic Review," 9.

24. U.S. Fish and Wildlife Service, "Fish Migration - Atlantic Salmon," https://www.fws.gov (accessed 31 May 2021).

25. The following is based on, Dunn et. al., "The Importance of Migratory Connectivity for Global Ocean Policy," Proceedings Royal Society B 286 (2019).

26. Michael S. Webster et. al., "Links between Worlds: Unravelling Migratory Connectivity," Trends in Ecology \& Evolution, 17(2) (2002): 76-83.

27. Ibid., 77.

28. Ibid.

29. The total catch increased with 5,4 percent from the average of the last three years. See, FAO The State of World Fisheries and Aquaculture 2020. Sustainability in Action (Rome: FAO, 2020), 6.

30. Ibid., 7 .

31. Trevor Ward et al. cited in FAO, "The Ecosystem Approach to Fisheries," FAO Fisheries Technical Paper 443 (2003): 6.

32. Harden-Davies et al., "Rights of Nature: Perspectives for Global Ocean Stewardship," 4.

33. LOSC, Preamble Recital 3. 


\section{Elise fohansen et al.}

34. The LOSC takes a zonal approach to maritime jurisdiction, by distinguishing between maritime zones under national jurisdiction, such as the territorial sea, the exclusive economic zones and the continental shelf, and maritime zones beyond national jurisdiction, where the LOSC distinguishes between the high seas and the Area. For an overview, see, e.g., Yoshifumi Tanaka, The International Law of the Sea $3^{\text {rd }}$ ed. (Cambridge: Cambridge University Press, 2019), 3.

35. Ibid.

36. United Nations Agreement for the Implementation of the Provisions of the United Nations Convention on the Law of the Sea of 10 December 1982 relating to the Conservation and Management of Straddling Fish Stocks and Highly Migratory Fish Stocks (adopted 4 August 1995, entered into force 11 December 2001), 2167 UNTS 88.

37. Harden-Davies et al., "Rights of Nature: Perspectives for Global Ocean Stewardship," 4.

38. Convention on Biological Diversity (adopted 5 June 1992, entered into force 29 December 1993) 1760 UNTS 79.

39. Harden-Davies et al., "Rights of Nature: Perspectives for Global Ocean Stewardship," 4.

40. See, e.g., Mary George, "Transit Passage and Pollution Control in Straits under the 1982 Law of the Sea Convention," Ocean Development E International Law 33(2) (2002): 202.

41. See further, e.g., "Guideline for the Implementation of Ecosystem-based Approach in Maritime Spatial Planning (MSP) in the Baltic Sea Area," HELCOM, https://helcom.fi/media/ documents/Guideline-for-the-implementation-of-ecosystem-based-approach-in-MSP-inthe-Baltic-Sea-area_June-2016.pdf (accessed 31 May 2021).

42. See, e.g., Donald R. Rothwell and Tim Stephens, The International Law of the Sea $2^{\text {nd }}$ ed. (Oxford: Hart Publishing, 2016) 257. See also, Articles 22(3)(a), 39(2)(a), 41(4)-(5) of the LOSC.

43. This paragraph draws on, Elise Johansen, "The Role of the Oceans in Regulating the Earth's Climate, Legal Perspectives," in The Law of the Sea and Climate Change, Solutions and Constraints, eds. Johansen, Busch and Jakobsen.

44. This paragraph is based on, Philipp P. Nickels, "Bridging the Land-Sea-Interface: Regime Interaction in the Context of Ocean Acidification," (2021, PhD Project Presentation) (on file with the author).

45. LOSC, Articles 207 and 212; see further, Donald R. Rothwell and Tim Stephens, The International Law of the Sea, 407.

46. For an analysis, see Frank Wacht, "Article 207," in United Nations Convention on the Law of the Sea, A Commentary, ed. Alexander Proelss (Munich: CH Beck, 2017), 1378-1390; Frank Wacht, "Article 212," ibid, 1443-1451.

47. Karen N. Scott, "Legal Aspects of Climate Change," in The Future of Ocean Governance and Capacity Development, Essays in Honor of Elisabeth Mann Borgese (1918-2002) ed. International Ocean Institute - Canada (Leiden: Brill, 2018), 169-174, 170.

48. Elise Johansen, Ingvild U. Jakobsen and Philipp P. Nickels, "The Law of the Sea as Part of the Climate Change Regime Complex," in The Law of the Sea and Climate Change, Solutions and Constraints, eds. Johansen, Busch and Jakobsen, 387.

49. See, e.g., Alan Boyle, "Protecting the Marine Environment from Climate Change: The LOSC Part XII Regime," in ibid, 94.

50. Scott, "Ocean Acidification: A Due Diligence Obligation under the LOSC," 408; James Harrison, Saving the Oceans Through Law: The International Legal Framework for the Protection of the Marine Environment (Oxford: Oxford University Press, 2017), 267 et seq.

51. Karen N. Scott, "Ocean Acidification and Sustainable Development Goal 14: A Goal but No Target?," in The Marine Environment and United Nations Sustainable Development Goal 14, eds. Myron H. Nordquist et al. (Leiden: Brill, 2019), 323-341, 329.

52. United Nations Framework Convention on Climate Change (adopted 9 May 1992, entered into force 21 March 1994), 1771 UNTS 107. 


\section{A Marine-Biology-Centric Definition of Ocean Connectivity and the Law of the Sea}

53. Kyoto Protocol to the United Nations Framework Convention on Climate Change (adopted 11 December 1997, entered into force 16 February 2005), 37 ILM 22.

54. Paris Agreement (adopted 12 December 2015, entered into force 4 November 2016) 1771 UNTS 107.

55. Tanaka, The International Law of the Sea, 394.

56. UNGA, "Transforming our World: The 2030 Agenda for Sustainable Development," (25 September 2015) UN Doc A/RES/70/1.

57. For a discussion, see Scott, "Ocean Acidification and Sustainable Development Goal 14: A Goal but No Target?".

58. Ibid, 324.

59. Kal Raustiala and David G. Victor, "The Regime Complex for Plant Genetic Resources," International Organisation 58 (2004): 279.

60. Ibid.

61. Ibid.

62. Scott, "Ocean Acidification and Sustainable Development Goal 14: A Goal but No Target?," 329.

63. CBD, COP 5 Decision V/6 Ecosystem Approach, COP Decision (cbd.int) (accessed 31 May 2021).

64. However, traces of the principle are found in the provisions concerning the conservation of depending and associated species, Article 194 (5) of the LOSC with regard to measures to prevent, reduce and control pollution of the marine environment and provisions governing the Area.

65. 1995 UNFSA, Articles 5 and 8(3).

66. Article 5 of the 1995 UNSA requires "[s]tate parties to ... minimize pollution, waste, discards, catch by lost or abandoned gear, catch of non-target species - in particular endangered species - and more generally to protect biodiversity in the marine environment”. Furthermore, Article 5 obliges the state parties to adopt, where necessary, conservation measures for species belonging to the same ecosystem.

67. See, e.g, Tore Henriksen, Geir Hønneland and Are K. Sydnes, Law and Politics in Ocean Governance: The UN Fish Stocks Agreement and Regional Fisheries Management Regimes (Leiden/ Boston: Martinius Nijhoff Publishers, 2006). Henriksen and Hønneland address this particular issue on page 28 .

68. FAO, Code of Conduct for Responsible Fisheries (Rome: FAO, 1995) http://www.fao.org/3/ a-v9878e.pdf. (accessed 31 May 2021). For more information about the FAO, see "About FAO," http://www.fao.org/about/en/ (accessed 31 May 2021).

69. In the aftermath of the adoption, the FAO has also developed several technical guidelines, monitoring systems and forums to operationalize the approach. See, Serge M. Garcia and Kevern L. Cochrane, "Ecosystem Approach to Fisheries: A Review of Implementation Guidelines," ICES fournal of Marine Science 62 (2005): 311.

70. See, e.g., FAO, "The Ecosystem Approach to Fisheries," FAO Fisheries Technical Paper 443 (2003).

71. Jeremy B. C. Jackson et al., "Historical Overfishing and the Recent Collapse of Coastal Ecosystems," Science 293(5530) (2001): 629.

72. Terje T. Løbach et al., "Regional Fisheries Management Organizations and Advisory Bodies. Activities and Developments, 2000-2017," FAO Fisheries and Aquaculture Technical Paper 651 (2020): 1, https://doi.org/10.4060/ca7843en (accessed 31 May 2021).

73. Catch by lost or abandoned gear is a phenomenon that occurs when lost or abandoned gear is left in the water, and induces catch of marine organisms without human control. See, e.g., Tatsuro Matsuoka, Toshiko Nakashima and Naoki Nagasawa, "A Review of Ghost Fishing Scientific Approaches to Evaluation and Solutions," Fisheries Science 71 (2005): 691. 


\section{Elise fohansen et al.}

74. 1995 UNFSA, Article 5(f).

75. FAO, "The Ecosystem Approach to Fisheries," 36. The measures are also included in the subsequent adopted guidelines in FAO, "International Guidelines on Bycatch Management and Reduction of Discards," 17.

76. See, e.g., Eric Gilman, "Status of International Monitoring and Management of Abandoned, Lost and Discarded Fishing Gear and Ghost Fishing," Marine Policy 60 (2015); and Eric Gilman, Kelvin Passfield and Katrina Nakamura, "Performance of Regional Fisheries Management Organizations: Ecosystem-based Governance of Bycatch and Discards," Fish and Fisheries 15(2) (2014).

77. See, e.g., Wesley S. Patrick and Jason S. Link, "Myths that Continue to Impede Progress in Ecosystem-Based Fisheries Management," Fisheries 40(4) (2015): 157.

78. See, e.g., Scott, "Ocean Acidification: A Due Diligence Obligation under the LOSC," 402.

79. For a discussion, see, e.g., Gallo et al., "Ocean Commitments under the Paris Agreement," Nature Climate Change 7 (2017).

80. Utche T. Okpara et al., "A Social-ecological Systems Approach is Necessary to Achieve Land Degradation Neutrality," Environmental Science E Policy, 89 (2018): 59-66.

81. For a discussion, see Harden-Davies et al., "Rights of Nature: Perspectives for Global Ocean Stewardship," 4. 